\title{
Cardiovascular risk factors and increased carotid intima-media thickness in young patients with congenital adrenal hyperplasia due to 21-hydroxylase deficiency
}

Tânia Maria Barreto Rodrigues', Cristina Botelho Barra², Jovita Lane Soares Santos ${ }^{3}$, Eugênio Marcos Andrade Goulart ${ }^{4}$, Adaliene Versiani Matos Ferreira ${ }^{5}$, Ivani Novato Silva ${ }^{2}$

\begin{abstract}
Objective: Increased arterial intima-media thickness has been observed in adults with congenital adrenal hyperplasia (CAH) due to 21-hydroxylase deficiency (21-OHD). CAH has also been associated with obesity, insulin resistance, and hypertension. The aim of the present study was to compare youths with $\mathrm{CAH}$ with healthy, normal-weight individuals, evaluating carotid intima-media thickness (CIMT) and indicative factors of cardiovascular risk to seek for abnormalities in the CAH group. Subjects and methods: Clinical, biochemical, and ultrasonographic evaluations, according to published criteria, were performed in 113 subjects ( 5 to 20 years old): 40 patients with $21-\mathrm{OHD}$ and 73 healthy individuals matched for gender, pubertal status, and age. Results: Most CAH patients were female $(80 \%)$, salt-losers $(72.5 \%)$, and pubescent $(80 \%) ; 10(25 \%)$ patients were overweight. An increase in CIMT was observed both on the right $(p=0.0240)$ and left $(p=0.0003)$ sides in 38 CAH patients compared with the healthy individuals. The body mass index, BMI/age Z score, and systolic blood pressure (SBP) were higher in patients compared with controls ( $p<0.000$ and $p=0.0219$, respectively). Conclusions: Findings of increased CIMT, BMI, and SBP in young patients with 21-OHD indicate the need for early identification and intervention regarding cardiovascular risk. Validating these findings might result in improved therapeutic approaches for children with 21-OHD in the future. Arch Endocrinol Metab. 2015;59(6):541-7
\end{abstract}

Keywords

Adrenal hyperplasia, congenital; risk factors; carotid intima-media thickness; overweight; hypertension
1 Divisão de Endocrinologia Pediátrica, Faculdade de Medicina, Universidade Federal de Minas Gerais (UFMG), Belo Horizonte, MG; Departamento de Pediatria, Faculdade de Medicina, Universidade Federal de Juiz de Fora (UFJF), Campus Governador Valadares, Governador Valadares, MG, Brasil 2 Departamento de Pediatria, Divisão de Endocrinologia Pediátrica, Faculdade de Medicina, Universidade Federal de Minas Gerais (UFMG), Belo Horizonte, MG, Brasil

${ }^{3}$ Departamento de Anatomia e

Imagem, Faculdade de Medicina,

Universidade Federal de Minas Gerais (UFMG), Belo Horizonte, MG, Brasil

${ }^{4}$ Departamento de Pediatria, Faculdade de Medicina, Universidade Federal de Minas Gerais (UFMG), Belo Horizonte, MG, Brasil ${ }^{5}$ Departamento de Nutrição, Faculdade

de Enfermagem, Universidade

Federal de Minas Gerais (UFMG),

Belo Horizonte, MG, Brasil

\section{Correspondence to:}

Ivani Novato Silva

Divisão de Endocrinologia Infantil e do

Adolescente, Departamento de Pediatria, Faculdade de Medicina, Hospital das Clínicas Universidade Federal de Minas Gerais Av. Alfredo Balena 190, sala 267

30130-100 - Belo Horizonte, MG, Brasil ivanins@medicina.ufmg.br

Received on Aug/21/2015 Accepted on Sep/4/2015

DOI: 10.1590/2359-3997000000119

\section{INTRODUCTION}

$\mathrm{C}$ ongenital adrenal hyperplasia $(\mathrm{CAH})$ due to 21-hydroxylase deficiency (21-OHD) is a common autosomal recessive disorder associated with significant morbidity. Obesity, hypertension, and insulin resistance have been associated with $21-\mathrm{OHD}$, and these comorbidities may begin in childhood $(1,2)$. It is not known whether these metabolic abnormalities can be linked to the disease itself, its treatment, or both (3). As these metabolic abnormalities are related to the pathogenesis of atherosclerosis (4), increased cardiovascular risk might be expected for 21-OHD patients. Increased artery intima-media thickness (IMT) has also been reported in adults with the classical form of 21-OHD (5). Carotid intima-media thickness (CIMT) is an independent predictor of future cardiovascular risk $(6,7)$, and its increase has been reported in children with chronic diseases, suggesting early vascular injury in the paediatric group (8). CIMT also is positive correlated with body mass index (BMI) and systolic blood pressure (9). Presently, there is limited knowledge of comorbidities in children with 21$\mathrm{OHD}$, and it is uncertain whether they have increased cardiovascular risk.

The aim of the present study was to identify abnormalities indicative of cardiovascular risk, evaluating 
CIMT, clinical and biochemical parameters in youths with 21-OHD.

\section{SUBJECTS AND METHODS}

This cross-sectional study was approved by the Research Ethics Committee of Federal University of Minas Gerais, Brazil (ETIC302/08). All of the children, adolescents and legal guardians signed an informed written consent after receiving information concerning the study.

One-hundred-thirteen individuals were evaluated, including 40 patients diagnosed with classical $\mathrm{CAH}$ due to 21-OHD (29 of which were salt losers) and 73 healthy, normal-weight children and adolescents.

All 21-OHD patients, 5 to 20 years old, who were followed-up at the Pediatric Endocrinology Division of the Hospital das Clínicas, Federal University of Minas Gerais were selected to participate, based on the evaluation of medical records.

The diagnosis of 21-OHD was based on clinical and biochemical assessment and confirmed in $72.5 \%$ of the cases by genetic analysis of the CYP21A2 gene. All females presented with ambiguous genitalia at birth $(\mathrm{n}=32)$. No participant had other chronic disease or regularly received medication, aside from hormone replacement therapy for $\mathrm{CAH}$.

The healthy children were recruited from a public school located in Belo Horizonte, Minas Gerais, Brazil, and matched to the $\mathrm{CAH}$ group for age and gender. The inclusion criteria consisted of being in good health. The exclusion criteria were the presence or a history of any chronic disease, continuous use of medication, and being obese or overweight according to the World Health Organization (WHO) established criteria (body mass index for age and gender over the $85^{\text {th }}$ percentile) (10). The control group was not matched for weight because we found the community-based random sample of healthy controls more appropriate in our study setting. If BMI-matched controls had been used, we would not have been able to compare the prevalence of cardiovascular risk factors between the $\mathrm{CAH}$ and control children.

All participants underwent clinical, biochemical, and nutritional evaluation. A complete physical examination was conducted. The anthropometric parameters assessed according to the $\mathrm{WHO}$ criteria were measured using portable digital scales $\left(\mathrm{G}-\mathrm{Tech}^{\circledR}\right)$ to the nearest $0.1 \mathrm{~kg}$ for weight, and a wall-mounted stadiometer to the nearest $0.1 \mathrm{~cm}$ for height. Blood pressure was analysed following the Fourth Report on the Diagnosis, Evaluation, and
Treatment of High Blood Pressure in Children and Adolescents, according to age and height (11). Pubertal staging for females breast development and for testes size/ genitalia for males were evaluated using the Tanner criteria (12). To analyze the pubertal status the participants were classified as prepubescent (Tanner 1), early puberty (Tanner 2 and 3), and late puberty (Tanner 4 and 5).

Following overnight fasting, blood samples were collected between 7 and 8 a.m. for the biochemical assessment. Serum glucose, total cholesterol and fractions, and triglycerides were measured by colourimetric methods (VITROS ${ }^{\circledR}$ 5.1 FS Chemistry System, Buckinghamshire, UK). Insulin and androstenedione levels were measured by chemiluminescence assay (IMMULITE $^{\circledR} 1000$ Immunoassay System, Los Angeles, CA, USA), and $17 \alpha$-hydroxyprogesterone was measured by radioimmunoassay (Siemens Healthcare Diagnostics Inc., Los Angeles, CA, USA).

Insulin resistance was assessed by the Homeostatic Model Assessment for Insulin Resistance (HOMA-IR) according to the formula: insulin $(\mu \mathrm{U} / \mathrm{mL}) \mathrm{x}$ glucose $(\mathrm{mmol} / \mathrm{L}) / 22.5(13)$.

High-resolution B-mode ultrasonography was performed by a single experienced specialist in radiology and diagnostic imaging blinded to the status of the participants to measure the intima-media layer thickness and evaluate the colour Doppler flow characteristics of the carotid arteries. The recommendations of the Consensus Statement from the American Society of Echocardiography Carotid Intima-Media Thickness Task Force were followed (14).

The exams were conducted using a Toshiba Xario device model SSA-660A with a high-resolution multifrequency linear transducer adjusted to $12 \mathrm{MHz}$. B-mode colour photographic and Doppler velocimetry documentation was performed using image-acquisition software Image Explorer 3.1 for Windows.

After resting for $10 \mathrm{~min}$, the subjects were evaluated in the supine position with the neck slightly extended and inclined to $45^{\circ}$. Longitudinal and transverse sections of the right and left common carotid arteries (CCA), carotid bulbs, internal carotid arteries, and external carotid arteries were obtained using B-mode and colour Doppler ultrasound.

The ultrasound evaluation was conducted focusing on the identification of the intima-media layer and distinction of focal atherosclerotic plaques. Three measurements of the IMT of each right and left common carotid arteries were obtained in the $15 \mathrm{~mm}$ stretch below the 
bulb region, free from focal plaques, where the double lines pattern of the IMT can be clearly observed. Multiple measurements were averaged to report a mean IMT value for each artery. Colour Doppler flow examination of the internal and external common carotid arteries was conducted using technical parameters specific to the carotid arteries. Pulsed Doppler ultrasound was performed in the most distal segments of the internal and external common carotid arteries accessible to the exploratory probe with an insonation angle less than or equal to $60^{\circ}$ to obtain quantitative information through spectral analysis. The equipment settings used were the same as the ones used for the qualitative analysis.

\section{Statistical analysis}

Comparisons between cases and controls data were adjusted for pubertal status and were performed in two sets: all CAH patients versus controls and normal weight $\mathrm{CAH}$ patients versus controls.

Statistical analysis was performed using the Statistical Package for the Social Sciences (SPSS) for Windows version 19.0 (SPSS Corporation, Chicago, IL, USA) and EPI INFO version 6.04. The WHO AnthroPlus software version 1.0.4. (10) was used to calculate BMI. Normal distribution for the variables was tested using the Kolmogorov-Smirnov test. Descriptive statistics were performed, and data are presented as measures of central tendency and dispersion (median and mean \pm SD) for continuous variables and as proportions for categorical and quantitative variables. The Student's t-test was used to compare means, and the Mann-Whitney test was used to compare medians. The Chi-square test was used for group analysis. The Pearson correlation coefficients ( $r$ ) between CIMT and other variables were calculated. Statistical significance was defined as a p value $<0.05$.

\section{RESULTS}

Patients with 21-OHD were mostly salt-losers (72.5\%), females $(80 \%)$, and pubescent individuals $(80 \%$ Tanner stages 4 and 5 ). Both $\mathrm{CAH}$ patients and healthy control groups were similar as to gender $(\mathrm{p}=0.55)$, age $(\mathrm{p}=$ $0.45)$, and pubertal status $(\mathrm{p}=0.80)$. CAH patients were $14.3 \pm 4.4$ years old, were diagnosed with $\mathrm{CAH}$ at a median age of two months (0-120 months), and were three months old (0-120 months) when they began follow-up at the University Hospital. They reported good adherence to treatment according their medical records. The clinical characteristics of the subjects are presented in table 1 .
Table 1. Clinical characteristics of patients with $\mathrm{CAH}$ and healthy controls

\begin{tabular}{|c|c|c|c|}
\hline Variable & $\begin{array}{l}\text { Patients } \\
(n=40)\end{array}$ & $\begin{array}{c}\text { Controls } \\
(n=73)\end{array}$ & p-value \\
\hline Female/male & $32 / 08$ & $52 / 21$ & 0.55 \\
\hline $\mathrm{Age}^{\star}$ & $14.1(5.11-20.1)$ & $14.9(7.61-20.06)$ & 0.453 \\
\hline $\mathrm{BMI} /$ age Z-score $^{\dagger}$ & $0.30 \pm 0.90$ & $-0.53 \pm 0.85$ & $<0.001$ \\
\hline Pubertal status (n) & 40 & 73 & 0.80 \\
\hline Prepubescent & 2 & 6 & \\
\hline Early puberty & 6 & 12 & \\
\hline Late puberty & 32 & 55 & \\
\hline WC/H ratio & $0.44(0.38-0.57)$ & $0.41(0.36-0.55)$ & $<0.001$ \\
\hline $\mathrm{SBP}<{\mathrm{P} 90^{+}}^{+}$ & 27 & 58 & 0.219 \\
\hline $\mathrm{SBP} \geq \mathrm{PgO}^{\dagger}$ & 6 & 2 & \\
\hline $\mathrm{DBP}<{\mathrm{P} 90^{\dagger}}^{+}$ & 22 & 49 & 0.1695 \\
\hline $\mathrm{DBP} \geq \mathrm{P}^{\dagger}{ }^{\dagger}$ & 11 & 11 & \\
\hline
\end{tabular}

${ }^{*}$ Median (minimum-maximum); ${ }^{\dagger} \mathrm{n} \leq 18$ years old. $\mathrm{WC} / \mathrm{H}$ : waist circumference/height ratio. SBP: systolic blood pressure; DBP: diastolic blood pressure.

At their last visit, $\mathrm{CAH}$ patients were receiving a daily dose of $14.6 \pm 3.6 \mathrm{mg} / \mathrm{m}^{2}$ of hydrocortisone. The salt-losers received fludrocortisone at an average dose of $100 \mu \mathrm{g} /$ day. CAH patients were shorter than controls with height/age Z-scores of $-0.36 \pm 1.41$ and $0.16 \pm 1.01$, respectively $(\mathrm{p}=0.033)$.

Twenty-five percent of the patients with 21-OHD were overweight $(\mathrm{n}=10)$, but none was obese. The BMI/ age $\mathrm{z}$ score of the whole CAH patients group $(n=40)$ was significantly higher than the $\mathrm{z}$ score of the control group $(\mathrm{p}<0.001)$. The BMI/age $\mathrm{z}$ score of normal weight $\mathrm{CAH}$ patients $(\mathrm{n}=30)$ was also significantly greater than that of controls $(-0.12 \pm 0.71$ vs. $-0.53 \pm 0.85 ; \mathrm{p}=0.029)$.

When CAH patients under 18 years old $(\mathrm{n}=33)$ were compared with control individuals of the same age group $(\mathrm{n}=60)$ higher systolic blood pressure $(\mathrm{SBP})$ levels $(\geq 90$ centiles) were found in $\mathrm{CAH}$ patients $(\mathrm{p}=0.0219)$. Although there were also more patients $(33 \%)$ presenting with diastolic blood pressure (DBP) levels $\geq 90$ centiles when compared with the controls (18\%), the difference was not statistically significant $(\mathrm{p}=0.1695)$. No difference was found in systolic $(\mathrm{p}=0.34)$ and diastolic blood pressure $(\mathrm{p}=0.13)$ between the salt-losing $\mathrm{CAH}$ patients and those exhibiting the simple virilising form.

The results of the biochemical evaluations of the investigated subjects are presented in table 2 . The serum lipid and insulin levels were similar in patients and controls, except for high-density lipoprotein cholesterol (HDL-c), which was lower in the $\mathrm{CAH}$ group. The $\mathrm{CAH}$ patients also exhibited significantly lower glucose concentration than controls, but the values of HOMA-IR were similar in both groups. 
Table 2. Biochemical characteristics of patients with $\mathrm{CAH}$ and healthy controls

\begin{tabular}{|c|c|c|c|}
\hline Variable & $\begin{array}{l}\text { Patients } \\
(n=40)\end{array}$ & $\begin{array}{l}\text { Controls } \\
(n=73)\end{array}$ & p-value \\
\hline $\begin{array}{l}\text { 17 } \alpha \text {-hydroxyprogesterone } \\
(\mathrm{nmol} / \mathrm{L})^{\star}\end{array}$ & $\begin{array}{c}130.59 \\
(1.36-1215.03)\end{array}$ & $\begin{array}{c}2.84 \\
(0.24-18.18)\end{array}$ & $<0.001$ \\
\hline $\begin{array}{l}\text { Androstenedione } \\
(\mathrm{nmol} / \mathrm{L})^{\star}\end{array}$ & $\begin{array}{c}20.46 \\
(0.73-34.92)\end{array}$ & $\begin{array}{c}6.00 \\
(0.73-20.95)\end{array}$ & 0.0001 \\
\hline Glucose $(\mathrm{mmol} / \mathrm{L})^{\star \star}$ & $4.16 \pm 0.44$ & $4.50 \pm 0.33$ & $<0.001$ \\
\hline Insulin (pmol/L) $)^{*}$ & $\begin{array}{c}27.98 \\
(14.35-150.67)\end{array}$ & $\begin{array}{c}34.72 \\
(14.35-116.95)\end{array}$ & 0.322 \\
\hline HOMA-IR** & $1.07 \pm 0.90$ & $1.13 \pm 0.77$ & 0.25 \\
\hline Triglycerides $(\mathrm{mmol} / \mathrm{L})^{*}$ & $\begin{array}{c}0.85 \\
(0.28-2.19)\end{array}$ & $\begin{array}{c}0.76 \\
(0.37-2.52)\end{array}$ & 0.931 \\
\hline Total-c $(\mathrm{mmol} / \mathrm{L})^{\star *}$ & $4.03 \pm 0.88$ & $4.19 \pm 0.86$ & 0.316 \\
\hline $\mathrm{HDL}-\mathrm{c}(\mathrm{mmol} / \mathrm{L})^{\star *}$ & $1.22 \pm 0.32$ & $1.35 \pm 0.29$ & 0.046 \\
\hline LDL-c (mmol/L) $)^{\star *}$ & $2.39 \pm 0.81$ & $2.44 \pm 0.68$ & 0.745 \\
\hline
\end{tabular}

* Median (minimum-maximum); ${ }^{\star \star}$ Mean \pm SD.

HOMA-IR: Homeostatic Model Assessment for Insulin Resistance.

Ultrasonography of the carotid arteries was performed in 60 adolescents, 38 21-OHD patients and 22 healthy individuals. Both CAH patients and healthy children were similar as to age ( $\mathrm{p}=0,286)$, and pubertal status $(\mathrm{p}=0.992)$. CAH patients had significantly increased CIMT $(\mathrm{RC}=0.47 \pm 0.05 ; \mathrm{LC}=0.48 \pm 0.04)$ compared with the control group $(\mathrm{RC}=0.42 \pm 0.09$; $\mathrm{LC}=0.4 \mathrm{l} \pm 0.10)$ both in the right $(\mathrm{p}=0.0240)$ and left $(\mathrm{p}=0.0003)$ sides. The subset of normal weight $\mathrm{CAH}$ patients also showed significantly increased CIMT when compared with the control group, as shown in figure 1 . Among female patients, both RCIMT $(0,50 \pm$ $0.07 \times 0.42 \pm 0.07)$ and LCIMT $(0.50 \pm 0.06 \times 0.42 \pm$ 0.08 ) were significantly greater in $\mathrm{CAH}$ patients when compared with controls $(\mathrm{p}=0.002 \mathrm{l}$ and $\mathrm{p}=0.0006$, respectively). No difference was observed for males.

During the last four years before CIMT evaluation, cumulative hydrocortisone dosis data from 29 of the $40 \mathrm{CAH}$ patients $(72 \%)$ was retrieved. According to the medical records these 29 children received a mean daily dose of $13.38 \pm 2.84 \mathrm{mg} / \mathrm{m}^{2}$ of hydrocortisone over $41.83 \pm 10.44$ months of follow-up. No significant association between hydrocortisone dose and CIMT could be

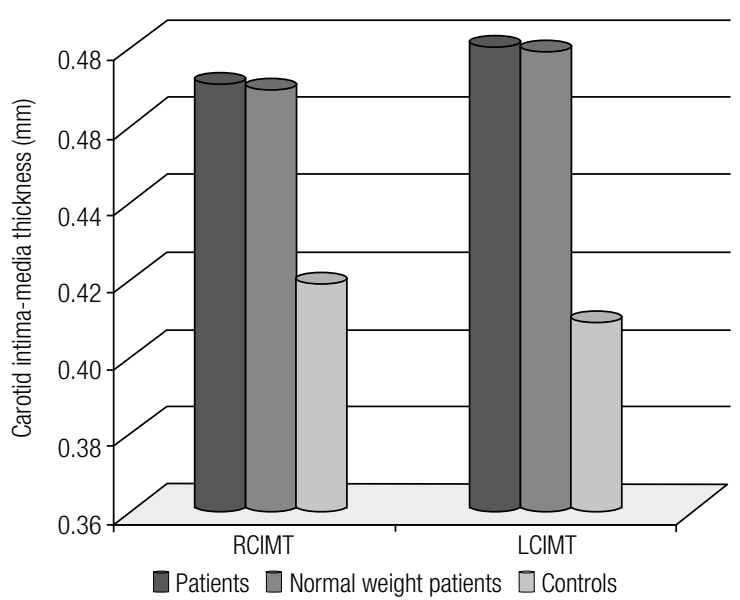

Figure 1. Carotid intima-media thickness in young patients with $\mathrm{CAH}$ and healthy controls: right (RCIMT) and left (LCIMT) sides.

demonstrated in these patients (right carotid: $\mathrm{r}=-0.05 \mathrm{r} 2$ $=0.00 \mathrm{p}>0.05$; left carotid: $\mathrm{r}=-0.24 \mathrm{r} 2=0.06 \mathrm{p}>0.05$ ).

No significant associations were also demonstrated between CIMT and BMI, between CIMT and blood pressure, and between CIMT and all metabolic parameters, including serum androstenedione, total cholesterol and fractions, triglycerides, and HOMA-IR.

Doppler assessment of the carotid arteries did not show signs of obstruction of the blood flow, which maintained its laminar pattern and normal velocity.

\section{DISCUSSION}

Young patients with 21-OHD in this study had increased CIMT when compared with the healthy children.

A significant increase in CIMT, a surrogate marker of atherosclerosis, has been reported in adult $\mathrm{CAH}$ patients suggesting increased cardiovascular risk (5). It is known the process of atherosclerosis starts during infancy (6). Two recent reports showed an increased CIMT in children and adolescents with classical CAH $(15,16)$, as was found in the present study. Findings of increased CIMT in childhood suggest that vascular lesions might be amenable to early detection, and that $\mathrm{CAH}$ patients may benefit from specific interventions to address their cardiovascular risk (1).

Table 3. Carotid intima-media thickness (mean $\pm \mathrm{DP}$ ) in patients with $\mathrm{CAH}$ and healthy controls

\begin{tabular}{|c|c|c|c|c|c|c|}
\hline & Patients $(n=38)$ & Controls $(n=22)$ & p-value & $\begin{array}{c}\text { Normal weight } \\
\text { patients }(n=29)\end{array}$ & Controls $(n=22)$ & p-value \\
\hline RCIMT & $0.47+0.05$ & $0.42+0.09$ & 0.0240 & $0.47+0.05$ & $0.42+0.09$ & 0.0168 \\
\hline LCIMT & $0.48+0.04$ & $0.41+0.10$ & 0.0003 & $0.48+0.04$ & $0.41+0.10$ & 0.0005 \\
\hline
\end{tabular}

RCIMT: right carotid intima-media thickness; LCIMT: left carotid intima-media thickness. 
Another study showing brachial artery dysfunction on ultrasound without carotid disease in 14 young $\mathrm{CAH}$ patients, when compared with obese or healthy individuals, lends further support to such early and targeted intervention (17).

Ultrasonographic assessment of CIMT is a wellestablished examination for screening individuals at cardiovascular risk (7). A hindrance to the wider use of CIMT measurements in the paediatric population is the lack of standardisation of CIMT values in this age group. Values above the $95^{\text {th }}$ percentile of the control group (CIMT $>0.475 \mathrm{~mm}$ ) were considered abnormal in a study of children with high cardiovascular risk (6). However, one should take into consideration that a slight linear increase in CIMT with age is observed among healthy children, preventing the use of a single reference value in childhood (9). Comparison with healthy controls in studies increases the reliability of the results, but this comparison is not feasible in everyday clinical practice.

Chronic diseases in children such as dyslipidaemia, type 1 diabetes mellitus, and chronic renal failure have been associated with increased CIMT (8). The relationships of obesity and high blood pressure with increased CIMT have also been reported in adolescents (18). Notwithstanding the previously mentioned difficulties, a systematic review concluded that despite heterogeneous methodology in ultrasonographic assessment, a significant increase in CIMT could be demonstrated in 55 out of 67 studies in the paediatric population (8). Therefore, screening for cardiovascular risk in several chronic diseases including $\mathrm{CAH}$ during childhood might be achieved using CIMT measurements.

The reasons for the presumably increased cardiovascular risk in 21-OHD patients remain unknown. Due to the current inability to replace the physiological secretion of cortisol perfectly, children with CAH may present with periods of endogenous hyperandrogenism and iatrogenic hypercortisolism during treatment. The difficulty of devising an ideal treatment for those patients is widely agreed upon (3). Glucocorticoid replacement may increase the risk of cardiovascular disease through multiple pathways, resulting in a trade-off between benefit and harm. In a recently published report, children and adolescents with $\mathrm{CAH}$ were observed to be obese, have a higher BP, demonstrate impaired glucose tolerance with reduced insulin sensitivity, and have an increased CIMT compared with their healthy counterparts. The authors did not find a correlation between these variables and mean daily hydrocortisone dose, but they hypothesized that there might be a cumulative effect of glucocorticoid therapy over years (16). The greater risk of metabolic complications in patients with CAH might also be related to the pharmacogenetics of an individual response to glucocorticoids (19). The greater sensitivity to glucocorticoids of some patients results in a therapeutic overdose that is not necessarily related to improved control but exposes patients to developing metabolic complications (20).

We found glucocorticoid replacement in the studied group was uniform and appropriate, following the current recommendations and consistent with previous findings of therapeutic efficacy in the same group of children $(21,22)$. Follow-up was performed systematically at the same medical facility, and patients had no clinical signs of glucocorticoid excess or suppressed levels of serum steroids. Contrary to what would be expected in glucocorticoid excess, they showed lower mean glucose levels than controls. Furthermore, we could not demonstrate a correlation between mean hydrocortisone dose and CIMT. Taken together these findings suggest that the increased CIMT should not be attributed to treatment-related effects, however, this possibility cannot be ruled out.

Twenty-five percent of the patients with 21-OHD were overweight. Increased body fat in childhood is an early risk factor for morbidity and mortality in adult life (8) and has already been reported in CAH children (23). Possible metabolic consequences of increased body fat are dyslipidaemia and reduced insulin sensitivity, both of which are more common in $\mathrm{CAH}$ patients (24). Increased body fat in 21-OHD patients might reflect general population trends, as is currently occurring in Brazil, where a prevalence of $20.5 \%$ of overweight and $4 \%$ of obesity for children 10 to 19 years old has been reported, according to data from Instituto Brasileiro de Geografia e Estatística (IBGE) (25). Nonetheless, the $\mathrm{BMI}$ in the studied CAH group was higher than in the control group, even when normal weight $\mathrm{CAH}$ patients were compared with healthy controls.

Obesity and familial predisposition were reported as significant determining factors of an adverse metabolic profile in young patients with $\mathrm{CAH}$ (26). On the other hand, it has been suggested that increased body fat in classical CAH children could reflect the effects of lifetime glucocorticoid therapy $(27,28)$, as stated before.

The association between increased CIMT and higher androgen levels reported in obese female adolescents (29) 
notes another aetiology in increased cardiovascular risk, namely, hyperandrogenism, which is a frequent finding in CAH patients. This possibility cannot also be ruled out in the present study. However, serum androstenedione levels did not show a significant association with CIMT.

Another relevant previously reported finding was the increased SBP in CAH patients in both obese and normal weight individuals (30). Increased SBP has been associated with increased CIMT. In a longitudinal evaluation of nearly 100 Latin-American children diagnosed with metabolic syndrome, SBP and 2-h postprandial glucose were the best predictors of CIMT, even when taking into consideration other components of the syndrome (31). This association could not be proven in the present study. Although such increases in blood pressure have been associated with obesity and increased CIMT in adolescents (18), it is difficult to assess the relative contribution of each variable. Again, the treatment regimen has been implicated in the increase of blood pressure in children with CAH (32). Further studies are needed to achieve a better understanding of these associations and to assess other possibilities in the development of hypertension in patients with $\mathrm{CAH}$.

It was observed that cardiovascular risk factors detected in childhood such as elevated LDL-c, SBP, and BMI were associated with increased CIMT and that progression to atherosclerosis may be predicted in childhood independent of risk factors identified later in adulthood (33). Most studies show normal lipid profiles in CAH patients (24). On the other hand, a higher HDL-c may independently predict a lower cardiovascular risk (34). Therefore, the lower levels of HDL-c among patients with $\mathrm{CAH}$, as was found in this study, may represent an additional cardiovascular risk factor for these children. These findings give support for intervention programmes intended to reduce cardiovascular risk factors during childhood (35).

This cross-sectional study presents some limitations. The most important of these limitations is that the sample size is small for ascertaining associations. This small sample size did not permit drawing conclusions regarding the causes of increased CIMT. However, an increased CIMT in CAH children, as shown in this study, has also been recently reported by two others research groups $(15,16)$, which indicates that these findings will likely be confirmed through further trials.

Although the physiopathology of the metabolic abnormalities occurring in $\mathrm{CAH}$ is currently unknown, early detection of these abnormalities may be of great relevance. Reversibility of early atherosclerotic alterations has been reported in obese prepubescent children with increased CIMT who showed a significant reduction in carotid lesion size with weight loss (35).

We conclude that increased CIMT might be an early indication of greater cardiovascular risk in children and adolescents with $\mathrm{CAH}$, as previously reported in adults. Abnormal SBP and BMI may also represent independent risk factors for these children. These findings of increased CIMT, BMI, and SBP in young patients with CAH require confirmation and might lead to improved therapeutic approaches for children with $\mathrm{CAH}$ in the future.

Acknowledgments: this research was partially supported by grants from Fapemig - Fundação de Amparo à Pesquisa do Estado de Minas Gerais (Minas Gerais State Research Foundation) \# CDS-APQ-00435-09 and Pró-Reitoria de Pesquisa da Universidade Federal de Minas Gerais.

Disclosure: no potential conflict of interest relevant to this article was reported.

\section{REFERENCES}

1. Arlt W, Willis DS, Wild SH, Krone N, Doherty EJ, Hahner S, et al.; United Kingdom Congenital Adrenal Hyperplasia Adult Study Executive (CaHASE). Health status of adults with congenital adrenal hyperplasia: a cohort study of 203 patients. J Clin Endocrinol Metab. 2010;95(11):5110-21.

2. Mooij CF, Kroese JM, Claahsen-van der Grinten HL, Tack CJ, Hermus AR. Unfavourable trends in cardiovascular and metabolic risk in paediatric and adult patients with congenital adrenal hyperplasia? Clin Endocrinol (Oxf). 2010;73(2):137-46.

3. Charmandari E, Brook CGD, Hindmarsh P. Classic congenital adrenal hyperplasia and puberty. Eur J Endocrinol. 2004;151 Suppl 3:U77-82.

4. Charmandari E, Weise M, Bornstein SR, Eisenhofer G, Keil MF, Chrousos GP, et al. Children with classic congenital adrenal hyperplasia have elevated serum leptin concentrations and insulin resistance: potential clinical implications. J Clin Endocrinol Metabol. 2002;87(5):2114-20.

5. Sartorato P, Zulian E, Benedini S, Mariniello B, Schiavi F, Bilora $F$, et al. Cardiovascular risk factors and ultrasound evaluation of intima-media thickness at common carotids, carotid bulbs, and femoral and abdominal aorta arteries in patients with classic congenital adrenal hyperplasia due to 21-hydroxylase deficiency. J Clin Endocrinol Metab. 2007;92(3):1015-18.

6. Järvisalo MJ, Jartti L, Näntö-Salonen K, Irjala K, RönnemaaT, Hartiala JJ, et al. Increased aortic intima-media thickness a marker of preclinical atherosclerosis in high-risk children. Circulation. 2001;104(24):2943-7.

7. Hurst RT, Ng DW, Kendall C, Khandheria B. Clinical use of carotid intima-media thickness: review of the literature. J Am Soc Echocardiogr. 2007;20(7):907-14.

8. Lamotte C, Iliescu C, Libersa C, Gottrand F. Increased intimamedia thickness of the carotid artery in childhood: a systematic review of observational studies. Eur J Pediatr. 2011;170(6):719-29. 
9. Jourdan C, Wühl E, Litwin M, Fahr K, Trelewicz J, Jobs K, et al. Normative values for intima-media thickness and distensibility of large arteries in healthy adolescents. J Hypertens. 2005;23(9):1707-15.

10. World Health Organization 2009 AnthroPlus for personal computers manual: Software for assessing growth of the word's children and adolescents. Available at: http://www.who.int/growthref/ tools/en. Accessed on: Aug 12, 2013.

11. National High Blood Pressure Education Program Working Group on High Blood Pressure in Children and Adolescents. The fourth report on the diagnosis, evaluation, and treatment of high blood pressure in children and adolescents. Pediatrics. 2004;114(2 Suppl 4th Report):555-76.

12. Tanner JM. Psysical growth and development. In: Forjar JO, Amell CC, editors. Textbook of paediatrics. Edinburgh: Churchill Livingstone, 1978. p. 249-303.

13. Matthews DR, Hosker JP, Rudenski AS, Naylor BA, Treacher DF, Turner RC. Homeostasis model assessment: insulin resistance and beta-cell function from fasting plasma glucose and insulin concentrations in man. Diabetologia. 1985;28(7):412-19.

14. Stein JH, Korcarz CE, Hurst RT, Lonn E, Kendall CB, Mohler ER, et al.; American Society of Echocardiography Carotid Intima-Media Thickness Task Force. Use of carotid ultrasound to identify subclinical vascular disease and evaluate cardiovascular disease risk: a consensus statement from the American Society of Echocardiography Carotid Intima-Media Thickness Task Force. J Am Society Echocardiogr. 2008;21(2):93-111.

15. Wasniewska M, Balsamo A, Valenzise M, Manganaro A, Faggioli $\mathrm{G}$, Bombaci $\mathrm{S}$, et al. Increased large artery intima media thickness in adolescents with either classic or non-classic congenital adrenal hyperplasia. J Endocrinol Invest. 2013;36(1):12-5.

16. Amr NH, Ahmed AY, Ibrain YA. Carotid Intima media thickness and other cardiovascular risk factors in children with congenital adrenal hyperplasia. J Endocrinol Invest. 2014;37(10):1001-8.

17. Harrington J, Peña AS, Gent R, Hirte C, Couper J. Adolescents with congenital adrenal hyperplasia because of 21-hydroxylase deficiency have vascular dysfunction. Clin Endocrinol (Oxf). 2012;76(6):837-42.

18. Lim SM, Kim HC, Lee HS, Lee JY, Suh M, Ahn SV. Association between blood pressure and carotid intima-media thickness. $J$ Pediatr. 2009;154(5):667-71.

19. Moreira RP, Gomes LG, Mendonca BB, BachegaTA. Impact of glucocorticoid receptor gene polymorphisms on the metabolic profile of adult patients with the classic 21-hydroxylase deficiency. PLoS One. 2012;7(9):e44893.

20. HanTS, Stimson RH, Rees DA, Krone N, Willis DS, Conway GS, et al.; United Kingdom Congenital adrenal Hyperplasia Adult Study Executive (CaHASE). Glucocorticoid treatment regimen and health outcomes in adults with congenital adrenal hyperplasia. Clin Endocrinol (Oxf). 2013;78(2):197-203.

21. Speiser PW, Azziz R, Baskin LS, Ghizzoni L, Hensle TW, Merke DP, et al.; Endocrine Society: Congenital adrenal hyperplasia due to steroid 21-hydroxylase deficiency: an Endocrine Society clinical practice guideline. J Clin Endocrinol Metab. 2010;95(9):4133-60.

22. Cordeiro GV, Silva IN, Goulart EMA, Chagas AJ, Kater CE. Final height in congenital adrenal hyperplasia: the dilemma of hyper- cortisolism versus hyperandrogenism. Arq Bras Endocrinol Metabol. 2013;57(2):126-31.

23. VölkI TM, Simm D, Beier C, Dörr HG. Obesity among children and adolescents with classic congenital adrenal hyperplasia due to 21-hydroxylase deficiency. Pediatrics. 2006;117(1);e98105.

24. Reisch N, Arlt W, Krone N. Health problems in congenital adrenal hyperplasia due to 21-hydroxylase deficiency. Horm Res Paediatr. 2011;76(2):73-85.

25. Instituto Brasileiro de Geografia e Estatística (IBGE). Pesquisa de orçamentos familiares. 2008-2009 despesas, rendimentos e condições de vida. Available at: http://www.ibge.gov.br/home/ estatistica/populacao/condicaodevida/pof/2008_2009. Accessed on: Aug 12, 2013.

26. Moreira RP, Villares SM, Madureira G, Mendonca BB, Bachega TA. Obesity and familial predisposition are significant determining factors of an adverse metabolic profile in young patients with congenital adrenal hyperplasia. Horm Res Paediatr. 2013;80(2):111-8.

27. Finkielstain GP, Kim MS, Sinaii N, Nishitani M, Van Ryzin C, Hill SC, et al. Clinical characteristics of a cohort of 244 patients with congenital adrenal hyperplasia. J Clin Endocrinol Metab. 2012;97(12):4429-38.

28. Williams RM, Deeb A, Ong KK, Bich W, Murgatroyd PR, Hughes IA, et al. Insulin sensitivity and body composition in children with classical and nonclassical congenital adrenal hyperplasia. Clin Endocrinol (Oxf). 2010;72(2):155-60.

29. de Sousa G, Brodoswki C, Kleber M, Wunsch R, Reinehr T. Association between androgens, intima-media thickness and the metabolic syndrome in obese adolescent girls. Clin Endocrinol (Oxf). 2010;72(6):770-4.

30. VölkITM, Simm D, Dötsch J, Rascher W, Dörr HG. Altered 24-hour blood pressure profiles in children and adolescents with classical congenital adrenal hyperplasia due to 21-hydroxylase deficiency. J Clin Endocrinol Metab. 2006;91(12):4888-95.

31. Toledo-Corral CM, Ventura EE, Hodis HN, Weigensberg MJ, Lane $\mathrm{CJ}$, LiY, et al. Persistence of the metabolic syndrome and its influence on carotid artery intima media thickness in overweight Latino children. Atherosclerosis. 2009;206(2):594-8.

32. Subbarayan A, Dattani MT, Peters CJ, Hindmarsh PC. Cardiovascular risk factors in children and adolescents with congenital adrenal hyperplasia due to 21-hydroxylase deficiency. Clin Endocrinol (Oxf). 2014;80(4):471-7.

33. Juonala M, Viikari JS, Kähönen M, Taittonen L, Laitinen T, HutriKähönen $\mathrm{N}$, et al. Life-time risk factors and progression of carotid atherosclerosis in young adults: the Cardiovascular Risk in Young Finns study. Eur Heart J. 2010;31(14):1745-51.

34. Abbasi A, Corpeleijn E, Gansevoort RT, Gans RO, Hillege HL, Stolk $\mathrm{RP}$, et al. Role of HDL cholesterol and estimates of HDL particle composition in future development of type 2 diabetes in the general population: the PREVEND Study. J Clin Endocrinol Metab. 2013;98(8):e1352-59.

35. Wunsch R, de Sousa G, Toschke AM, Reinehr T. Intima-media thickness in obese children before and after weight loss. Pediatrics. 2006;118(6):2334-40. 